\title{
Phase Transformation and Impurity Redistribution During Pulsed Laser Irradiation of Amorphous Silicon Layers
}

\section{Citation}

Narayan, J., C.W. White, O.W. Holland, and Michael J. Aziz. 1984. Phase Transformation and impurity redistribution during pulsed laser irradiation of amorphous silicon layers. Journal of Applied Physics 56, no. 6: 1821-1830.

\section{Published Version}

http://dx.doi.org/10.1063/1.334192

\section{Permanent link}

http://nrs.harvard.edu/urn-3:HUL.InstRepos:3693707

\section{Terms of Use}

This article was downloaded from Harvard University's DASH repository, and is made available under the terms and conditions applicable to Other Posted Material, as set forth at http:// nrs.harvard.edu/urn-3:HUL.InstRepos:dash.current.terms-of-use\#LAA

\section{Share Your Story}

The Harvard community has made this article openly available.

Please share how this access benefits you. Submit a story.

\section{Accessibility}




\title{
Phase transformation and impurity redistribution during pulsed laser irradiation of amorphous sillicon layers ${ }^{a}$
}

\author{
J. Narayan, C. W. White, O. W. Holland, and M. J. Aziz \\ Solid State Divison, Oak Ridge National Laboratory, Oak Ridge, Tennessee 37831
}

(Received 26 March 1984; accepted for publication 27 April 1984)

\begin{abstract}
Microstructural changes and impurity redistribution have been studied in ${ }^{30} \mathrm{Si}^{+},,{ }^{75} \mathrm{As}^{+}-{ }^{63} \mathrm{Cu}^{+}$, and ${ }^{115} \mathrm{In}^{+}$-implanted, laser-annealed amorphous silicon layers for various pulse energy densities. Electron microscopy showed the formation of two distinct polycrystalline regions after irradiation with pulse energy densities below the threshold for "defect-free" annealing. A large polycrystalline (LP) region is found at the surface; a fine polycrystalline (FP) region lies below the $L P$ and any remaining amorphous material. The extent of impurity redistribution, determined by Rutherford backscattering measurements, was much greater in the LP region than in the FP region, indicating a very short melt lifetime in the latter. Accumulation of $\mathrm{Cu}$ and $\mathrm{In}$ at the free surface was found, indicating motion of an interface towards the free surface during growth of the large polycrystals. Similarly, accumulation was found at the FP-amorphous Si boundary, indicating motion of an interface away from the free surface during growth of the fine polycrystals. The LP thickness was found to correspond to the maximum depth of melting calculated by a heat-flow program. These results indicate that the FP layer forms by explosive crystallization.
\end{abstract}

\section{INTRODUCTION}

It is now well established that pullsed lasers can be used to remove ion implantation damage in semiconductors. ${ }^{1.2}$ The basic mechanism involves melting beyond the boundary of ion implantation damage layer, and the underlying crystalline substrate so that the "defect-free" substrate could provide a seed for crystal growth. Below this threshold of pulse energy density, in which case the melt front penetrates only partway through the amorphous layer, we discovered the formation of two distinct microstructural regions: a large polycrystalline (LP) region followed by a fine polycrystalline (FP) region. The FP region is evidently formed primarily by explosive recrystallization. ${ }^{3,4}$ The phenomenon of explosive recrystallization is referred to a process in which a crystallizing interface advances rapidly or runs away from a source that was responsible for its initiation. ${ }^{5,6}$

In this paper, we present results of a systemattic study on ${ }^{30} \mathrm{Si}^{+}-,{ }^{75} \mathrm{As}^{+}-,{ }^{63} \mathrm{Cu}^{+}-$, and ${ }^{115} \mathrm{In}^{+}$-implanted, amorphous silicon layers. The details of microstructural changes and concomitant impurity redistribution are described as a function of pulse energy density. The thickness of $L P$ and FP regions and associated phase transformations as a function of pulse energy density are of particular interest. The redistribution profiles of impurities such as As with equilibrium distribution coefficient near unity $\left(k_{0}=0.3\right)$ are compared with those of $\mathrm{Cu}$ and In with $k_{0}=4.0 \times 10^{-4}$. At velocities of solidification of several meters per second encountered during pulsed laser irradiation, the nonequilibrium distribution coefficient for As approaches unity, whereas for In and $\mathrm{Cu}$ it remains significantly lower than unity, resulting in significant interfacial segregation. From the extent of redistribution in the LP and FP regions, we can estimate the melt

\footnotetext{
2) Research sponsored by the Division of Materials Sciences, U. S. Department of Energy under contract W-7405-eng-26 with Union Carbide Corporation.
}

lifetimes. From the nature of segregation of $\mathrm{Cu}$ and $\mathrm{In}$ impurities, we obtain information on the mechanism of explosive recrystallization. ${ }^{5.6}$

\section{EXPERMMENT}

Single crystals of silicon (having $(100)$ orientation, 2-6 $\Omega$ cm resistivity, $500 \mu \mathrm{m}$ thick) were implanted with $200 \mathrm{keV}$ of ${ }^{30} \mathrm{Si}^{+}$ions to a dose of $1.5 \times 10^{16} \mathrm{~cm}^{-2}$ at liquid-nitrogen $\left(\mathrm{LN}_{2}\right)$ temperature, with $300 \mathrm{keV}{ }^{75} \mathrm{As}^{+}$ions to a dose of $3.3 \times 10^{16} \mathrm{~cm}^{-2}$, with $125 \mathrm{keV}{ }^{115} \mathrm{In}^{+}$ions to a dose of $1.0 \times 10^{16} \mathrm{~cm}^{-2}$ or with $160 \mathrm{keV}{ }^{63} \mathrm{Cu}^{+}$to a dose of $7.5 \times 10^{15} \mathrm{~cm}^{-2}$ at room temperature. The as-implanted specimens in all four cases contained an amorphous layer followed by a band of dislocation loops. The dislocation loops resulted from ion range straggling and clustering of interstitials that escaped the amorphous regions. The specimens implanted with ${ }^{30} \mathrm{Si}^{+},{ }^{75} \mathrm{As}^{+}$, and ${ }^{115} \mathrm{In}^{+}$ions were irradiated with single pulses of a ruby laser $(\lambda=0.693 \mu \mathrm{m}$; pulse duration, full width at hall maximum of a roughly Gaussian shape, $\sim 12 \times 10^{-9} \mathrm{~s}$; laser spot diameter $\sim 2 \mathrm{~cm}$ ) in which energy density was varied from 0.1 to $1.6 \mathrm{~J} \mathrm{~cm}^{-2}$. The specimens implanted with ${ }^{63} \mathrm{Cu}^{+}$ions were irradiated with single pulses of an excimer laser $(\lambda=0.308 \mu \mathrm{m}$, pulse duration $50 \times 10^{-9} \mathrm{~s}$ having roughly trapezoidal shape) in which pulse energy density was varied from 0.1 to 1.6 $\mathrm{J} \mathrm{cm}^{-2}$. The laser spot size varied from $20 \times 20$ to $5 \times 5 \mathrm{~mm}^{2}$. The spatial variations in energy density across the samples were estimated to be less than 5\%. The ion-implanted samples, before and after laser annealing, were ion thinned for cross-section electron microscopy and chemically thinned for plan-view microscopy. The transmission electron microscopy results were obtained using a Philips (EM-400) analytical microscope. The impurity distribution profiles before and after laser irradiation were determined by high-resolution Rutherford backscattering spectroscopy. 
RESULTS

\section{${ }^{30} \mathrm{Si}^{+}$implantation}

The as-implanted samples contained approximately 5000- $\AA$-thick amorphous layer followed by a 200 - $\AA$-wide band of dislocation loops [as shown in Fig. 1(a)]. No microstructural changes were observed after irradiation with 0.10 $\mathrm{J} \mathrm{cm}{ }^{-2}$ pulse. After irradiation with $0.20-\mathrm{J} \mathrm{cm}^{-2}$ pulse [Fig. 1(b)], the top 1850- $\AA$-thick amorphous layer turned into a FP region with average grain size of about $100 \AA$. The characteristics of the microstructures containing typical explosions provide strong evidence that explosive recrystallization $^{5,6}$ is involved in the formation of FP region. When the pulse energy density was increased to $0.30 \mathrm{~J} \mathrm{~cm}^{-2}$, we observed $\sim 800$ - $\AA$-wide $L P$ region near the surface followed by $2330-\AA$ FP region [Fig. 1 (c)]. At $0.50 \mathrm{~J} \mathrm{~cm}^{-2}$, the width of the LP region increased considerably from 800 (at 0.30 $\mathrm{J} \mathrm{cm}^{-2}$ ) to $1330 \AA$, while the thickness of the FP region increased slightly only to $2400 \AA$ [Fig. 1(d)]. When the pulse energy density was increased to $0.60 \mathrm{~J} \mathrm{~cm}^{-2}$, the thickness of the LP region increased to $2660 \AA$, while that of the FP region decreased to $1550 \AA$ [Fig. 1 (e)]. At $0.80 \mathrm{~J} \mathrm{~cm}^{-2}$, the thickness of the LP region increased further to $3330 \AA$ and that of the FP region decreased further to $860 \AA$ [Fig. 1(f)]. It was interesting to note that the microstructure of the FP
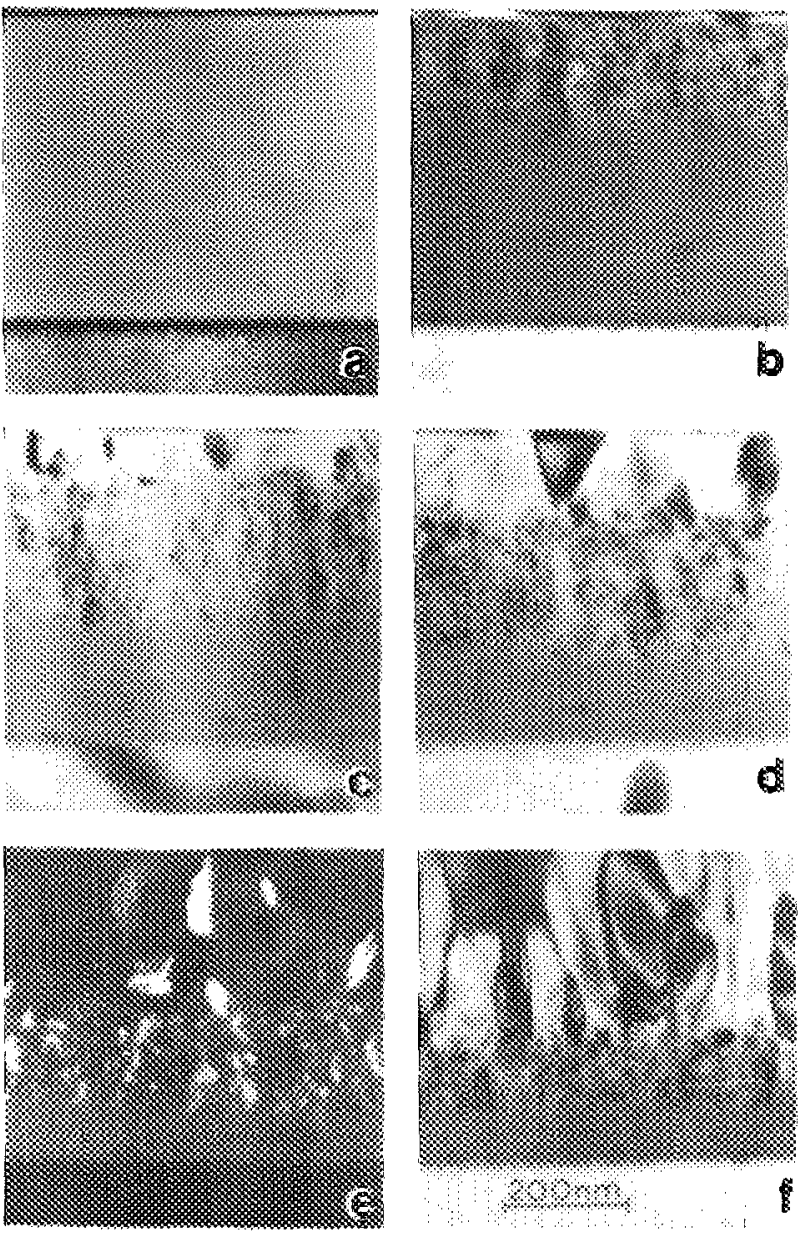

FIG. 1. Cross-section TEM micrographs from ${ }^{30} \mathrm{Si}^{+}$-ion-implanted specimens after 12-ns pulsed ruby laser irradiation with the following energy density: (a) As-implanted and $0.10 \mathrm{~J} \mathrm{~cm}^{-2} ;$ (b) 0.20 , (c) 0.30 , (d) 0.50 , (e) 0.60 , and (f) $0.80 \mathrm{~J} \mathrm{~cm}^{-2}$.

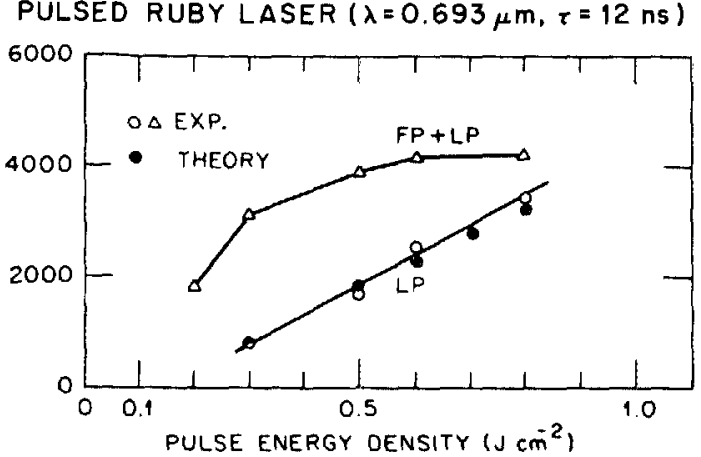

FIG. 2. Thickness of $(F P+L P)$ and $L P$ regions in ${ }^{30} \mathrm{Si}^{+}$-implanted specimens as a function of ruby pulse energy density. The filled circles show the calculated values.

region in Fig. $1(\mathrm{f})$ is more characteristic of bulk nucleation and growth than of the explosive growth.

Figure 2 shows a plot of depth of annealing as a function of pulse energy density. The thickness of the fine and large polycrystalline regions (FP + LP) shows a rapid initial increase with pulse energy density followed by a saturation. However, the thickness of the LP region exhibits a linear increase with pulse energy density. In Fig. 2, we have also included calculated depth of melting as a function of ruby pulse energy density. A heat-fiow program written by $M$. $O$. Thompson ${ }^{7}$ was used to calculate the depth of melting into the 5000-A-thick amorphous layer. The program is a finiteelement numerical solution of the heat-flow equation with the boundary condition that the temperature of the liquid-
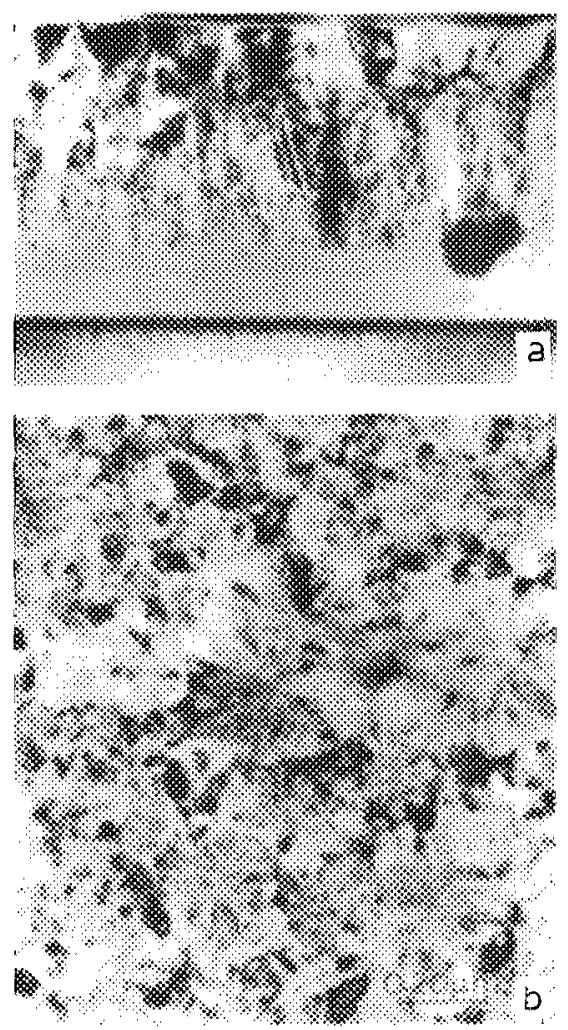

FIG. 3. (a) Cross-section TEM micrograph delineating $L P$ and FP regions in a $0.40 \mathrm{~J} \mathrm{~cm}^{-2}$ specimen. The exploding nuclei are seen in the FP region, and the marker shows a boundary between the LP and FP regions; (b) planview TEM micrograph from the same sample showing exploding nuclei (marked by arrows) in the FP region. 
amorphous interface is fixed at the melting point of $\alpha-\mathrm{Si}$, which was chosen to be $200 \mathrm{~K}$ below that of the crystal. The actual measured temporal pulse profiles were inserted into the calculations. The experimentally measured optical parameters were used in the calculations. The reflectivity used for liquid, amorphous, and crystalline silicon was 0.739 , 0.414 , and 0.336 , respectively; and the corresponding absorption coefficient was $1.01 \times 10^{6}, 9.84 \times 10^{4}$, and $1340 \exp (T / 427) \mathrm{cm}^{-1}$, respectively, ${ }^{8,9}$ The thermal conductivity, $0.02 \mathrm{~W} \mathrm{~cm}^{-1} \mathrm{~K}^{-1}$, is consistent with the data of Papa et al. ${ }^{10}$ Note that this value is about an order of magnitude lower than the thermal conductivity of crystalline silcon. The calculated maximum depths of melting, assuming normal melting from the resolidification back to the free surface, at various energy densities are plotted as filled circles in Fig. 2. The agreement between the measured thickness of $L P$ and calculated maximum depths of melting is excellent. By varying the melting point, thermal conductivity, and absorption coefficient of $\alpha$-Si within reasonable limits, it was not possible to fit the FP + LP curve, in contrast to the results of Webber et al. ${ }^{11}$ The agreement between our experimental results and the calculations is further evidence that the LP region corresponds to the initial depth of meiting and that the FP region is formed by a subsequent explosive recrystallization process. Figure 3(a) shows a cross-section TEN micrograph where LP and FP regions are clearly delineated. The FP region contains typical exploding nuclei, which start from the LP and FP boundary. A plan-view micrograph in Fig. 3(b) shows clearly the nuclei initiating the explosive recrystallization. The direction of crystallization of grains in the LP region with underlying FP region was found to be predominantly $\langle 110\rangle$. It should be noted that crystallization of the $L P$ region is unseeded. The formation of $\langle 110\rangle$ texture during unseeded crystallization and a model to account for these observation were reported in a previous paper. ${ }^{12}$

\section{${ }^{75}$ As + Implantation}

The specimens used for this investigation were implanted $300-\mathrm{keV}^{75} \mathrm{As}^{+}$ions to a dose of $3.3 \times 10^{16} \mathrm{~cm}^{-2}$, which contained a $3730-\AA$-thick amorphous layer followed by a $470-\AA$-wide band of dislocation loops. The width of the dislocation band increases with increasing substrate temperature because defects are mobile and escape amorphous regions to form loops. ${ }^{12}$ After irradiation with $0.20 \mathrm{~J} \mathrm{~cm}^{-2}$, we observed 450-LP and 2200-Å-thick FP regions [Fig. 4(a)]. At $0.41 \mathrm{~J} \mathrm{~cm}^{-2}$, the width of the LP region increases to $1350 \AA$, whereas the FP region thickness decreases to $1700 \AA$ [Fig. 4(b)]. Figure 4(c) shows a cross-section TEM micrograph from the $0.50-\mathrm{J} \mathrm{cm}^{-2}$ specimen, where the width of the LP region increases to $1950 \AA$ and that of the FP region decreases to $1300 \AA$. There is a boundary at a depth of $\sim 1500$ $\AA$ in the $\mathbb{L}$ region, indicating that the crystallization both from the front and back surfaces has occurred. This trend in thicknesses of FP and LP regions with energy density continues, as shown in Fig. $4(\mathrm{~d})$ for $0.60-\mathrm{J} \mathrm{cm}^{-2}$ specimens where the thickness of the LP and FP regions are 2530 and $500 \AA$, respectively. When the pulse energy density was increased to $0.83 \mathrm{~J} \mathrm{~cm}^{-2}$, it was interesting to note the formation of the FP region in the top $400-\AA$ layer, which was fol-
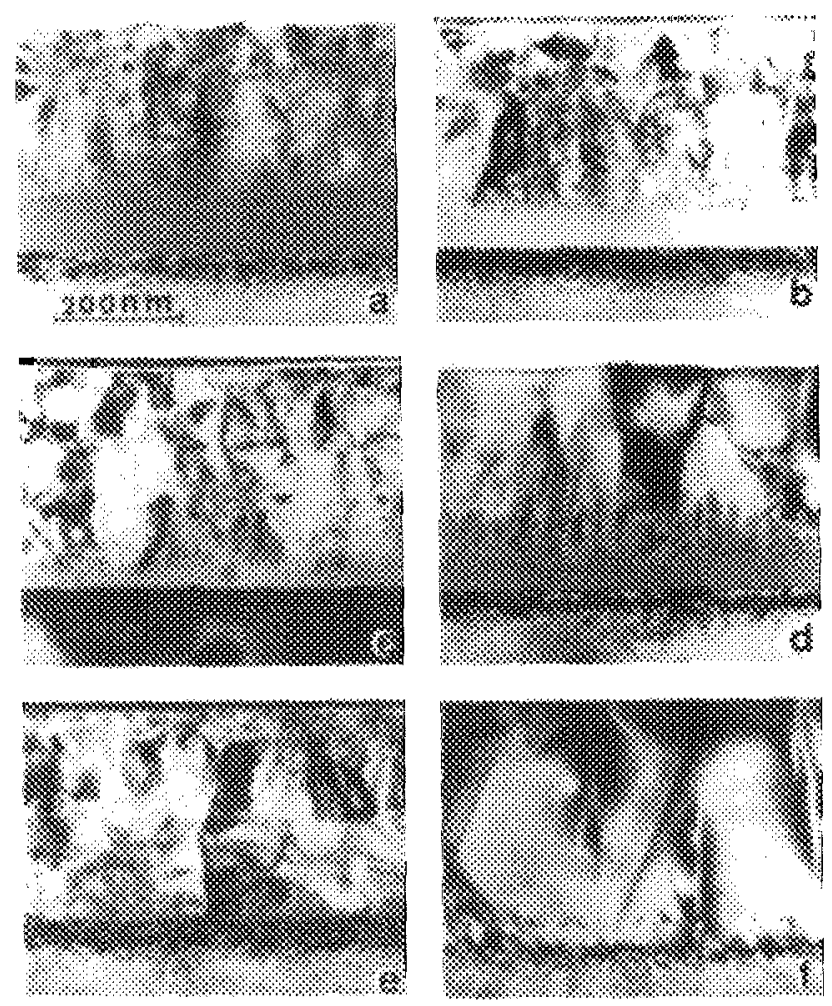

FIG. 4. Cross-section TEM micrographs from ${ }^{75} \mathrm{As}^{+}-1300 \mathrm{keV}, 3.3 \times 10^{16}$ $\mathrm{cm}^{-2}$ at RT)-implanted (100) Si specimens after pulsed ruby laser irradiation of the following energy densities: (a) 0.20 , (b) 0.41, (c) 0.50 , (d) 0.60 , (e) 0.83 , (f) $1.08 \mathrm{~J} \mathrm{~cm}^{-2}$. The formation of FP and LP regions are clearly elucidated. Notice the presence of FP region near the surface for $0.83 \mathrm{~J} \mathrm{~cm}^{-2}$ specimens.

lowed by a 3200-Å-wide LP region [Fig. 4(e)]. At this energy density also, the crystallization seems to be occurring both from the front and back sides. After the formation of fine polycrystals in the 400 - $\AA$-wide region near the surface, large crystallites are formed in the $400-1800 \AA$ region and in the 1800-3700 A region. The boundary between the two regions containing large crystallites is near the mean-projected range of $300-\mathrm{keV} \mathrm{As}{ }^{+}$ions. At this energy, the melt front reached the original amorphous-crystalline boundary. After $1.0-\mathrm{J} \mathrm{cm}^{-2}$ irradiation, the melting occurred also up to the

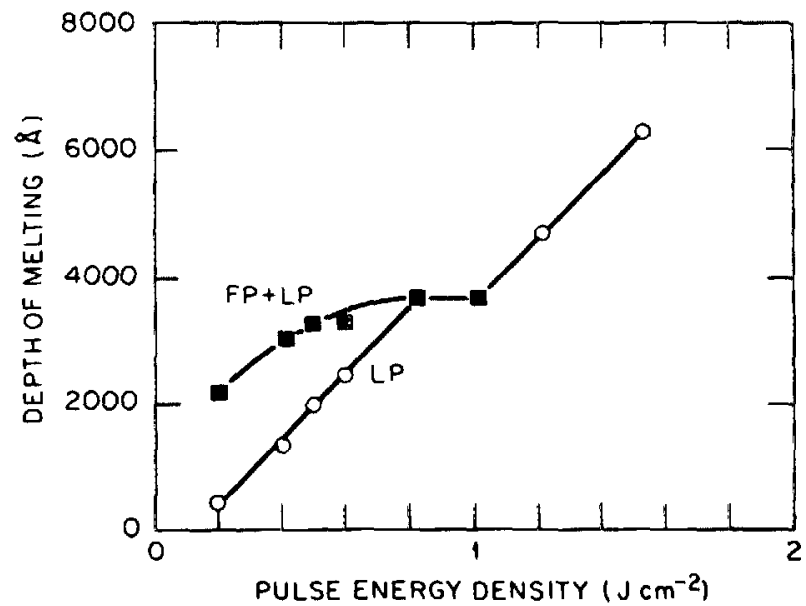

FIG. 5. The thickness (FP + LP) and LP regions as a function of ruby pulse energy from $\mathrm{As}^{+}$-implanted specimens. The thickness of $L P$ region increases linearly and then saturates while that of (FP + LP) region exhibits rapid initial rise followed by the saturation. 
amorphous-crystalline boundary. At $1.08 \mathrm{~J} \mathrm{~cm}^{-2}$, the crystalline region below the amorphous layer was just melted. The laser-melted and solidified region contains dislocations, which are formed due to the intersections of the melt front with dislocation loops and subsequent growth of this melted layer [Fig. 4(f)]. At 1.21 and $1.52 \mathrm{~J} \mathrm{~cm}^{-2}$, no dislocations were observed because the melt front penetrated below the dislocation band so that underlying "defect-free" substrate
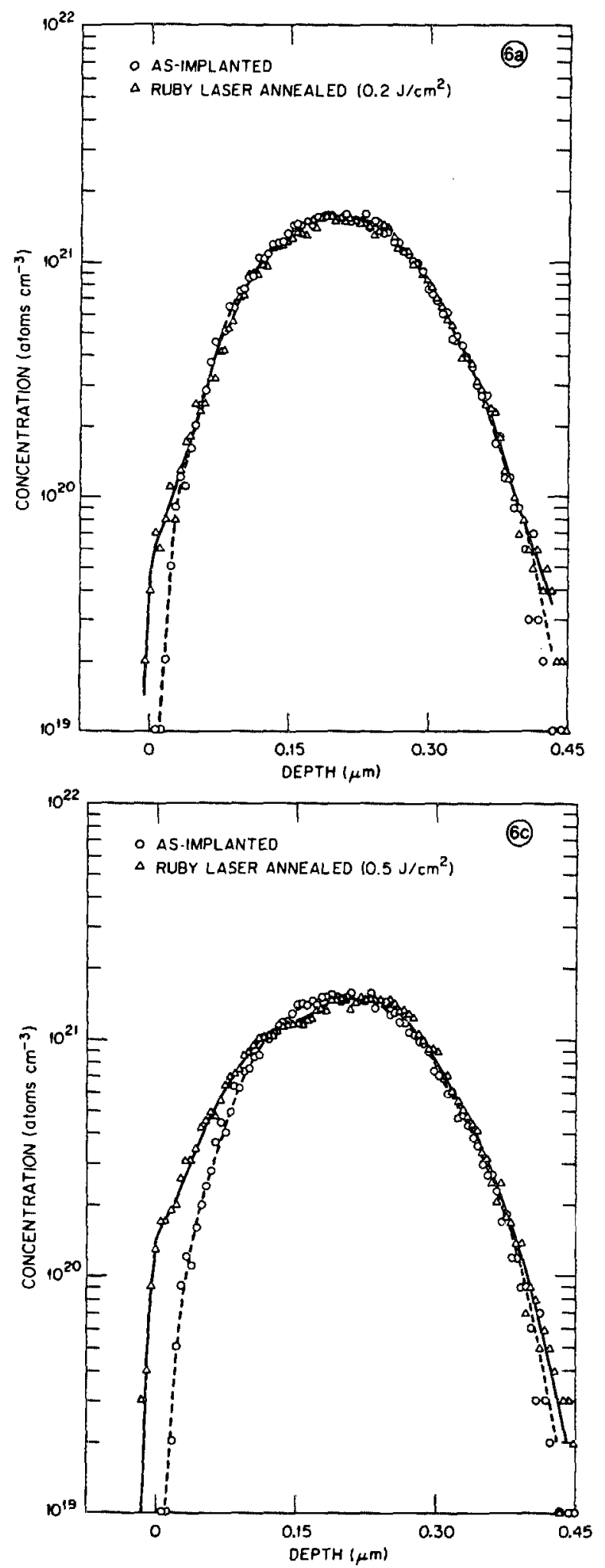

could act as a seed for crystal growth.

Figure 5 shows a plot of depth of annealing as a function of pulse energy density. It is interesting to note that the thickness of the $\amalg P$ region increases linearly with increasing pulse energy density. The thickness remains approximately constant between 0.83 and $1.0 \mathrm{~J} \mathrm{~cm}^{-2}$, and then it increases linearly again with pulse energy density. The total thickness of polycrystalline Si exhibits a rapid initial rise and then it
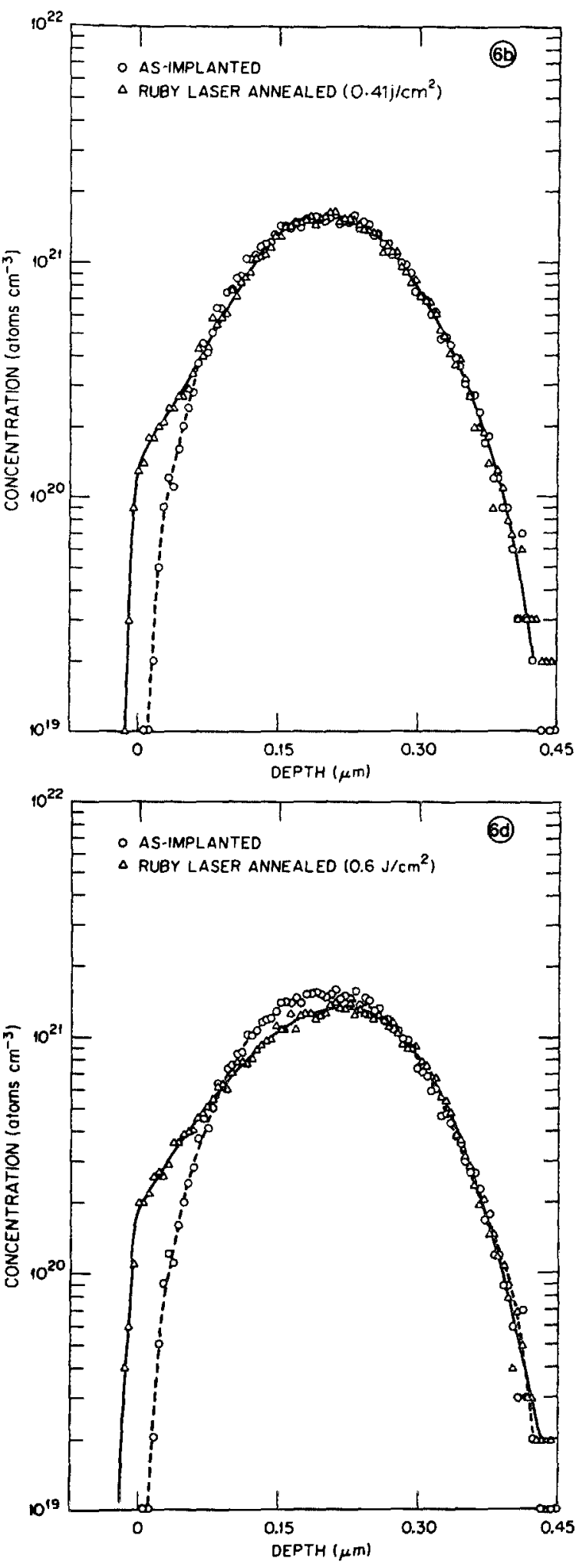

FIG. 6. Arsenic distributions profile before and after pulsed ruby laser irradiations. The redistribution in the LP region is clearly observed, whereas in the FP region the redistribution is less than $100 \AA$ : (a) Energy density $E=0.20$, (b) 0.41, (c) 0.50, (d) $0.60,(\mathrm{e}) 0.83,(\mathrm{f}) 1.08,(\mathrm{~g}) 1.21$, and (h) $1.53 \mathrm{~J} \mathrm{~cm}^{-2}$. 

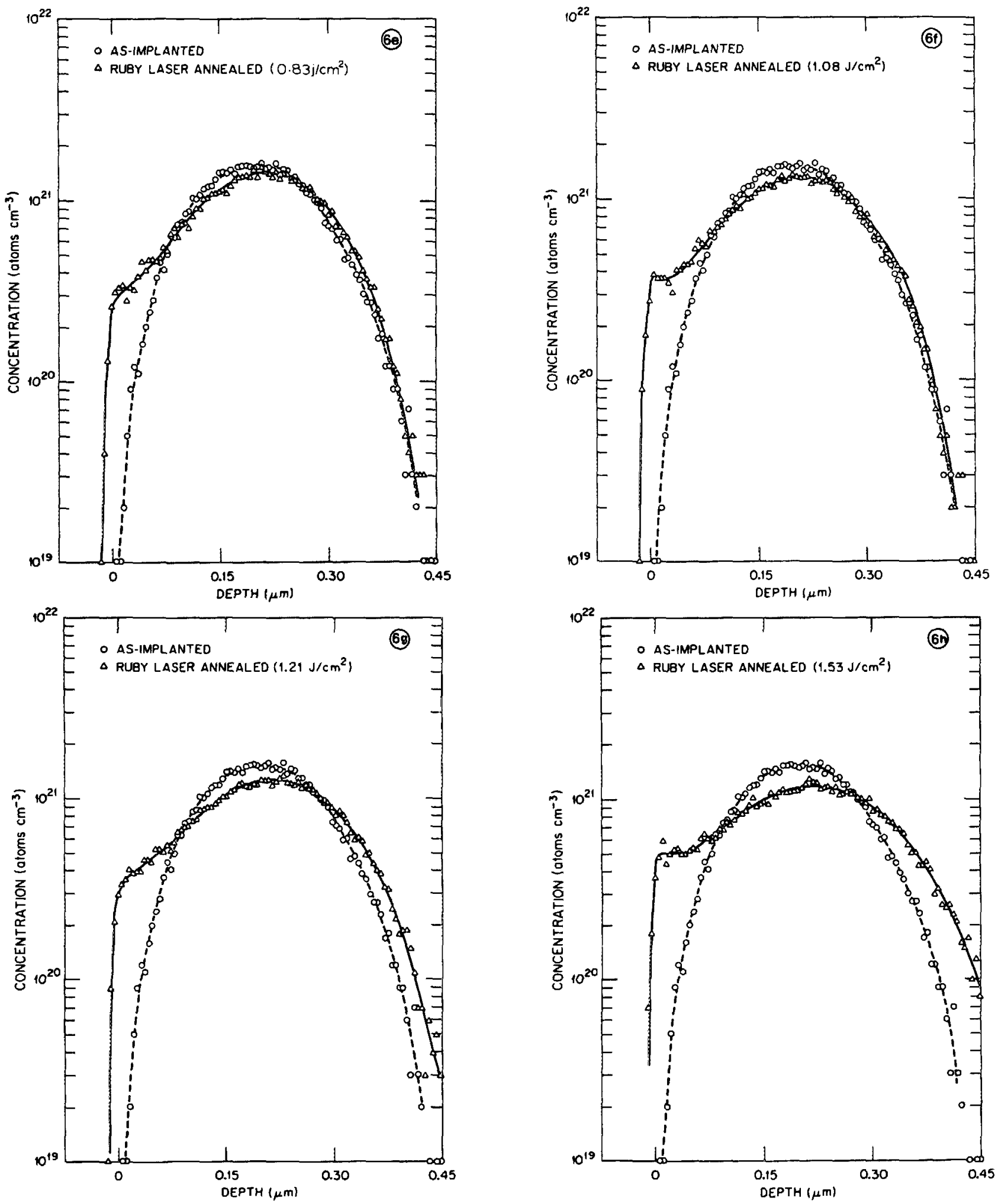

FIG. 6. Continued.

saturates at the thickness of the original amorphous layer. Also the thickness of the FP region decreases to zero for these energy densities.

The RBS measurements were made on companion samples before and after laser irradiation to study arsenic redistribution in the LP and FP regions. At $0.20 \mathrm{~J} \mathrm{~cm}^{-2}$, a large amount of arsenic redistribution is observed in a 450 - $\AA$-thick surface region [Fig. 6(a)], which is exactly the thickness of the LP region, as determined from Fig. 4(a). In the FP region, which follows the LP region, the extent of dopant redistribution is less than $100 \AA$ and cannot be easily detected by the RBS techniques. The arsenic distribution profiles before and after $0.41-\mathrm{J} \mathrm{cm}^{-2}$ pulse are shown in Fig. 6(b). A relatively large amount of arsenic redistribution is observed in the top $1350-\AA$-wide $L P$ region, whereas the redistribution in the following $1700-\AA$-wide FP region is very small. 
The arsenic redistribution for a $0.50-\mathrm{J} \mathrm{cm}^{-2}$ pulse is shown in Fig. 6(c). The arsenic distribution has changed significantly in the top $1950-\AA$-wide LP region, with an extra flatness in the profile at a depth of $1500 \AA$. As shown in Fig. $4(\mathrm{c})$, we observed crystallization both from the front and back sides for these specimens with a boundary at $\sim 1500-\AA$ depth. Figure 6(d) shows results for $0.60-\mathrm{J} \mathrm{cm}^{-2}$ pulses, where measurable arsenic redistribution occurs in the top 2530 - $\AA$-wide $L P$ region. The profile after laser irradiation does not show any intermediate flatness as was observed for $0.50-\mathrm{J} \mathrm{cm}^{-2}$ specimens. The TEM results [Fig. 4(d)] show that crystallization has occurred only from the back side in these specimens. For $0.83-\mathrm{J} \mathrm{cm}^{-2}$ specimens [Fig. 6(e)], the profile broadening is observed in the top 3900 -A -thick region. A large profile broadening in the top $400-\AA$-wide FP region indicates that the times available for diffusion are substantial. The microstructure of this region does not show any evidence of explosive events, indicating that the FP region is possibly formed by bulk nucleation and growth from highly supercooled liquid. Near the boundary (at a depth of $\sim 1500$ $\AA$ ) where the front and back crystallization fronts meet, the As profile indicates that the longest times for diffusion are available in this region. At $1.08 \mathrm{~J} \mathrm{~cm}^{-2}$, the profile broadening is also observed in the top $3900-\AA$-thick region similar to the $0.83 \mathrm{~J} \mathrm{~cm}^{-2}$ specimens, although the amount of broadening is slightly higher. The greater amount of broadening indicates longer times available for diffusion. The profile does not contain extra structure, indicating that crystallization occurred only from the back side. The latter is consistent with cross-section TEM results of Fig. $4(\mathrm{f})$. The RBS results before and after irradiation with 1.21- and 1.53$\mathrm{J} \mathrm{cm}^{-2}$ irradiations are shown in Fig. $6(\mathrm{~g})$ and $6(\mathrm{~h})$, respectively. The dopant profiles after irradiations in both cases show As diffusion to depths greater than $4500 \AA$. This depth is beyond the boundary of the ion-implantation damage and the TEM results show "defect-free" recrystallized regions for these energy densities.

\section{$\mathrm{Cu}^{+}$implantation}

The (100) silicon single crystals, after implantation with ${ }^{63} \mathrm{Cu}^{+}, 160 \mathrm{keV}, 7.5 \times 10^{15}$ ion $\mathrm{cm}^{-2}$, contained a $2600-\AA-$ thick amorphous layer followed by a $200-\AA$-wide dislocation band. After irradiation with $0.20 \mathrm{~J} \mathrm{~cm}^{-2}$, we observed 450 $\AA$ A.-wide LP region near the surface [Fig. 7(a)]. This is followed by 2000 - $\AA$-thick FP region, which is followed by about $150-\AA$-thick amorphous and 200 - $\AA$-wide band of dislocation loops. The explosive recrystallization events are clearly seen in the FP region. The microstructure in this case is similar to that produced by continuous wave laser or electron beam irradiation of amorphous layers in which crystallization velocity was estimated to be $10-12 \mathrm{~ms}^{-1}{ }^{5,6}$ However, it was erroneously labeled as SP-XCR, ${ }^{6}$ indicating that it occurs in solid phase. At $0.3 \mathrm{~J} \mathrm{~cm}^{-2}$, the thickness of the LP region increased to $750 \AA$ whereas the thickness of the explosively recrystallized $F P$ region decreased to $1550 \AA$. A similar trend in the thicknesses of the $L P$ and FP region was observed with increasing pulse energy density. At 0.8 $\mathrm{J} \mathrm{cm}^{-2}$, the entire amorphous layer, $2600 \AA$ thick, was found to turn into the LP region as shown in Fig. 7(b). Twins
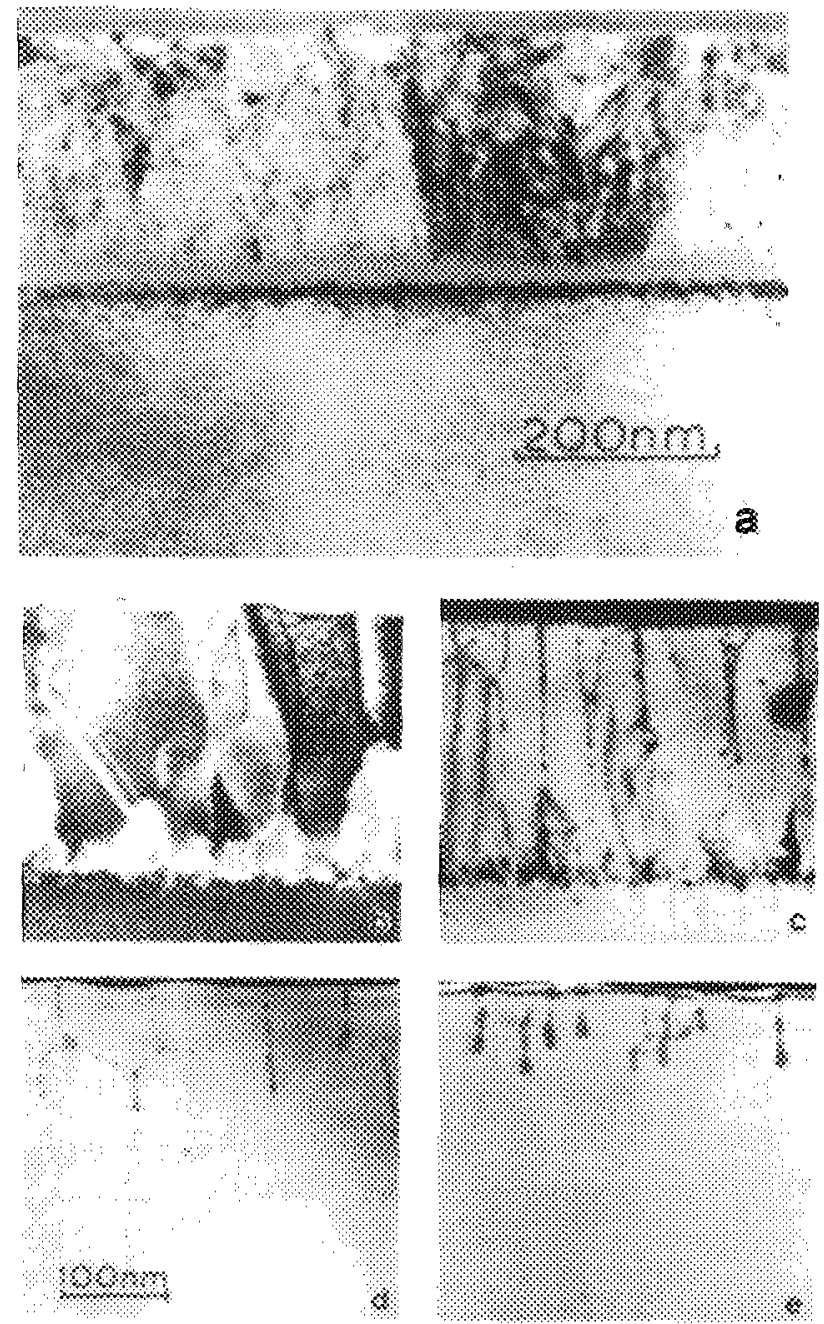

FIG. 7. (a) Cross-section TEM micrographs from ${ }^{63} \mathrm{Cu}^{+}-(160 \mathrm{keV}$, $7.5 \times 10^{15} \mathrm{~cm}^{-2}$ at RT) implanted (100) Si specimens after $0.20 \mathrm{~J} \mathrm{~cm}^{-2}$ excimer laser pulse; (b) $\mathrm{Cu}^{+}$-implanted samples after irradiation with 0.8 $\mathrm{J} \mathrm{cm}^{-2}$ excimer laser pulse, (c) and (d) $1.0 \mathrm{~J} \mathrm{~cm}^{-2}$ pulse, (e) $1.6 \mathrm{~J} \mathrm{~cm} \mathrm{~cm}^{-2}$ pulse.

were also observed near the original amorphous-crystalline interface. For $1.0 \mathrm{~J} \mathrm{~cm}^{-2}$ specimens [Fig. 7(c) and (d)], we observed dislocations and $\mathrm{Cu}$-rich cell walls. It was interesting to note the presence of cell walls along the dislocations, indicating a strong interaction between dislocations and growing cells. At this energy density, the meit front penetrated the entire amphorous layer and just intersected the underlying dislocation band. The dislocations intersected by the melt front grew back to the surface. Figure 7(d) was taken away from strong two-beam diffraction conditions, so that only Cu-rich cell walls are observed and the dislocations (revealed by strain contrast) are out of contrast. When the pulse energy density was increased to $1.6 \mathrm{~J} \mathrm{~cm}^{-2}$, only Cu-rich walls were observed in the top $750-\AA$ region, as shown in Fig. 7(e).

Figure 8(a) shows RBS profile after irradiation with a $0.2-1 \mathrm{~cm}^{-2}$ pulse. The as-implanted profile is Gaussian with a peak around $1250 \AA . \AA$. After irradiation with $0.2 \mathrm{~J} \mathrm{~cm}^{-2}$, the copper distribution profile has moved deeper into the sample with the following interesting features. The profile contains a distinct peak near the surface and a peak or shoulder around $2250 \AA$. At $0.3 \mathrm{~J} \mathrm{~cm}^{-2}$, we found a distinct peak near 

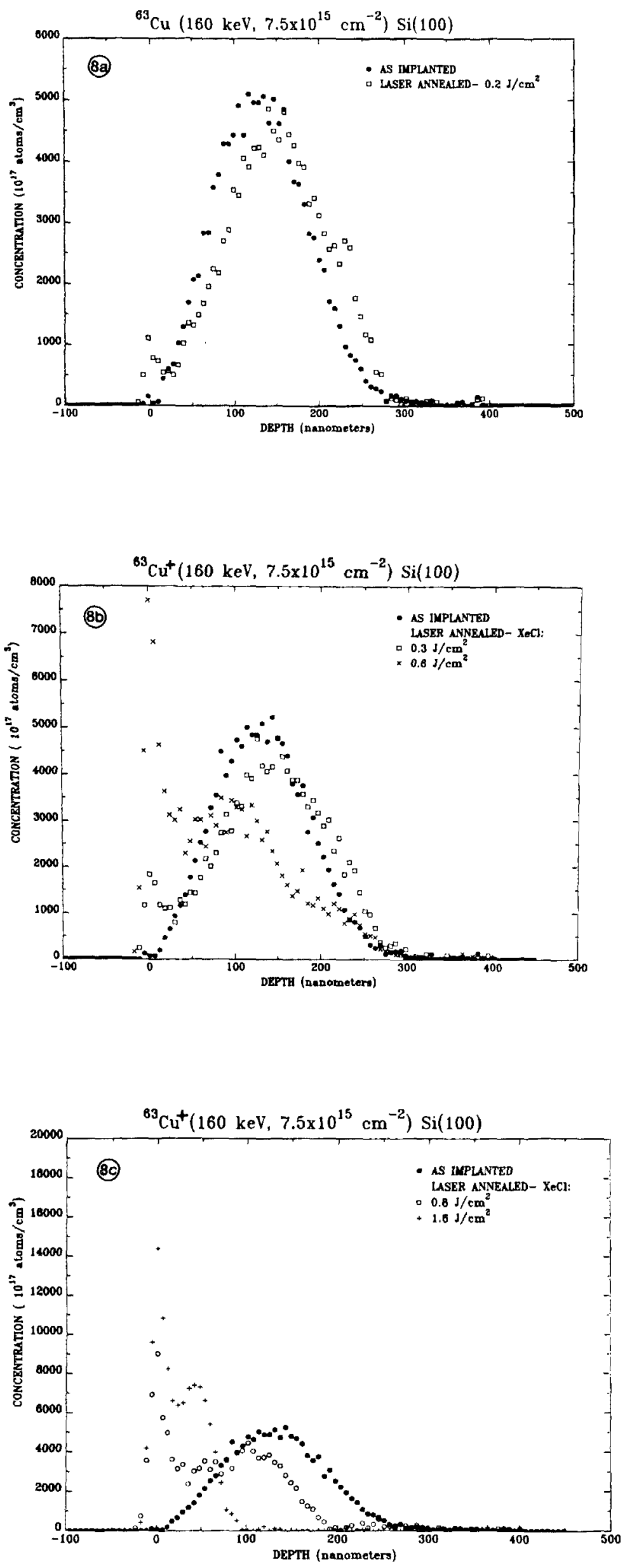

FIG. 8 (a). Copper distribution profiles before and after laser irradiation with $0.20 \mathrm{~J} \mathrm{~cm}^{-2}$ excimer laser pulse. The peak near the surface is formed due to the segregation in the LP region whereas the peak at the deeper regions is formed due to segregation in the FP region as a result of explosive recrystallization.
FIG. 8 (b). Copper distribution profiles before and after excimer laser irradiation with 0.30 and 0.60

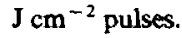


the surface, and a similar shoulder around $2500 \AA$. By increasing the pulse energy density to $0.6 \mathrm{~J} \mathrm{~cm}^{-2}$, a considerable segregation near the surface was observed. The amount of surface segregation increased with pulse energy density. Almost no copper was observed below $2000 \AA$ for $0.8 \mathrm{~J} \mathrm{~cm}^{-2}$ irradiations, as shown in Fig. $8(\mathrm{c})$. For $1.6-\mathrm{J} \mathrm{cm} \mathrm{cm}^{-2}$ irradiation, no copper was observed below $1000 \AA$ [Fig. 8(c)]. The surface segregation of copper involved normal regrowth toward the surface, whereas explosive recrystallization would cause segregation toward the deeper regions.

\section{In+ implants}

In this investigation, $(100)$ single crystals of silicon were implanted with $125-\mathrm{keV}^{115} \mathrm{In}^{+}$ions to a dose of $1.0 \times 10^{16}$ $\mathrm{cm}^{-2}$. The as-implanted samples contained a $1150-\AA$-thick amorphous layer followed by 400 - $\AA$-wide band of dislocation loops. After irradiation with $0.20-\mathrm{J} \mathrm{cm}^{-2}$ ruby laser pulse, we found $160-\AA$-wide LP regions followed by 640 - $\AA$ wide FP region [Fig. 9(a)]. The FP region contains a microstructure that is characteristic of explosive recrystallization. The RBS results on indium distribution profiles before and after laser irradiation are shown in Fig. 9(b). The as-implant-
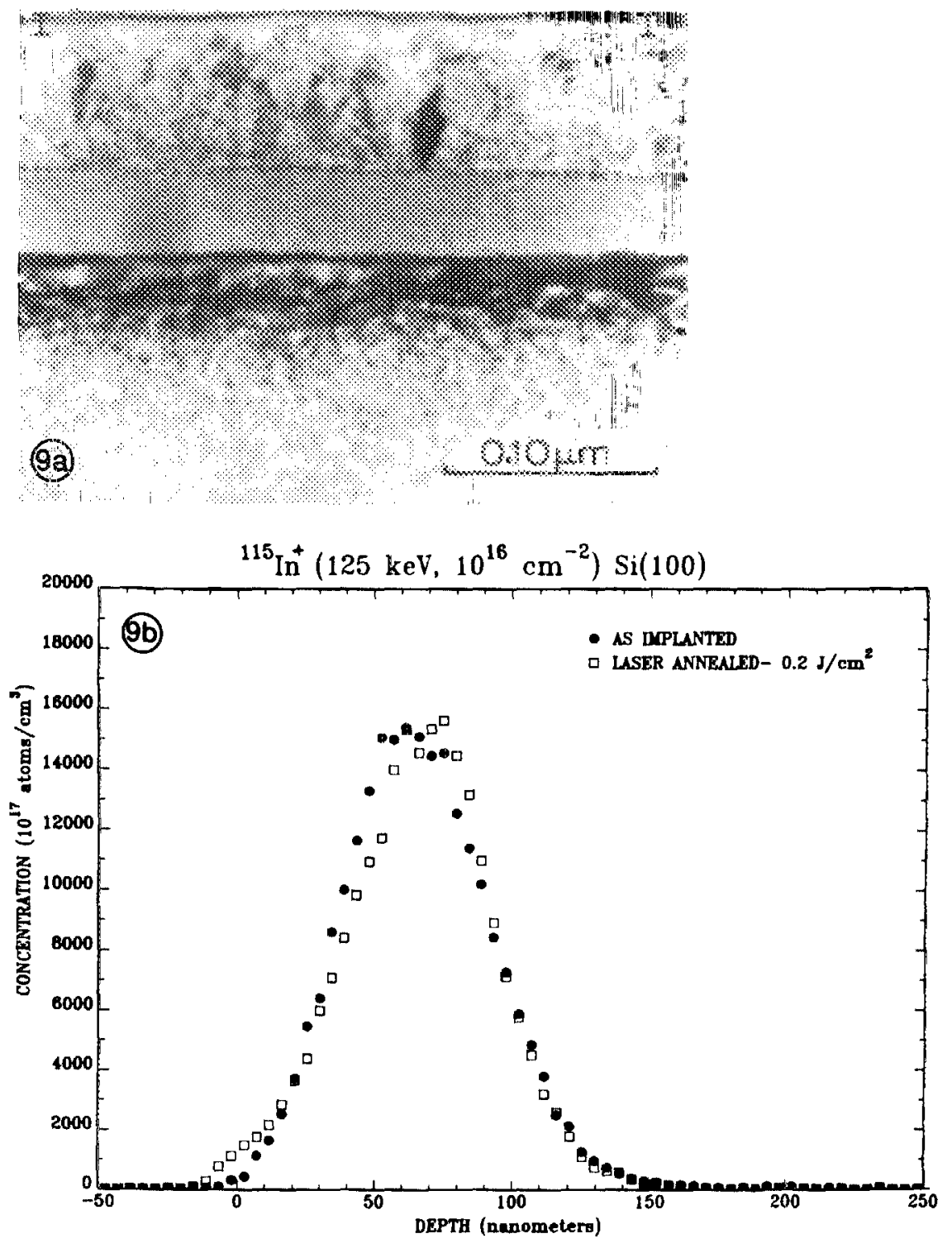

ed profile is Gaussian with a peak around $500 \AA$. After 0.20 $\mathbf{J ~ c m}{ }^{-2}$, it is interesting to note a small surface peak and a shoulder near $800-\AA$ depth. The peak of the profile shifts toward the deeper regions of the crystal. The surface peak in $\mathrm{In}^{+}$-implanted samples is not as conspicuous as in the case of $\mathrm{Cu}^{+}$-implanted samples.

\section{DISCUSSION}

The results clearly show the formation of large poiycrystalline (LP) and fine polycrystalline $\left(F^{P}\right)$ regions. The $F P$ regions generally contain microstructures that are characteristics of explosive recrystallization. Some of the characteristics of the explosive recrystallization process are the presence of exploding nuclei and directional texture. However, at pulse energies near $0.8 \mathrm{~J} / \mathrm{cm}^{-2}$, the microstructure of the $\mathrm{F}^{\mathrm{P}}$ region is not indicative of explosive recrystallization. The examples can be seen in Figs. 1(f) and 3(e). In these cases, it is possible that the fine grains are formed by bulk nucleation and growth of microcrystallites from highly supercooled liquid. However, from the average grain size in the FP region, Wood et al. ${ }^{14}$ have calculated nucleate rates that are much greater than those estimated by Tumbull. ${ }^{15}$
FIG. 9. (a) Cross-section TEM micrograph from ${ }^{115} \mathrm{In}^{+}\left(125 \mathrm{keV}, 1.0 \times 10^{16} \mathrm{~cm}^{-2}\right)$-implanted samples after irradiation with 0.20 $\mathrm{J} \mathrm{cm}^{-2}$. It contains $160-\AA ̊ . P$ and $640-\AA ̊$-wide FP region; (b) indium distribution profiles before and after $0.20-\mathrm{J} \mathrm{cm}^{-2}$ irradiation. After the irradiation, the profile contains a small peak near the surface. The centroid of the profile shifts to deeper regions. 
The thickness of LP region increases linearly with pulse energy density, while that of FP + LP region exhibits a rapid initial rise followed by a saturation at the thickness of original amorphous layer. The linear increase of the LP region is justified if it is assumed that this region melts with a planar interface.

The linear increase of LP thickness $d$ with pulse energy density can be understood in terms of a simple energy-balance equation once we realize that the layer thickness is the maximum depth of penetration of a planar melt front. The absorbed laser energy performs three separate heating tasks: it heats a small amount of solid just below the interface with $E_{T S}(d) \mathrm{J} / \mathrm{cm}^{2}$; it provides latent heat $L$ for the first-order phase transformation of $\alpha-S i$ to $l-S i$ with $L d \mathrm{~J} / \mathrm{cm}^{2}$, and it overheats the liquid near the surface to some extent with $E_{T L}(d) \mathrm{J} / \mathrm{cm}^{2}$. The key to the linear relationship is the thermal conductivity of the liquid being very much greater than that of the amorphous material. For when the melt front has penetrated to its deepest point, its velocity is zero and its temperature is $T_{M}$ and decreasing; consequently the product of thermal conductivity and temperature gradient on the liquid side of the interface must be less than that on the solid side. Thus, the temperature gradient in the liquid must be very small, and we can therefore set $E_{T L}(d) \approx 0$.

In addition, the high liquid and low $\alpha$-Si thermal conductivity mean that any volume element of $\alpha$-Si deeper than $d$ will receive most of its heating when the liquid is nearest, i.e., at its maximum penetration, independent of previous thermal history. Thus, $E_{T S}(d) \sim$ constant; it can be estimated by the threshold energy for melting times $\left(1-R_{s}\right)$, where $R_{s}$ is the solid reflectivity. Thus, we account for the linear behavior of $d$ with $E$, which should continue until the interface approaches the single-crystal "heat sink" closely enough that it affects the temperature profile in the hot amorphous layer. This should occur at a separation of roughly $D_{T} / v$, where $D_{T}$ is the thermal diffusivity and $v$ is the melt-in velocity. The heat-flow calculations yield $v \sim 20$ $\mathrm{m} / \mathrm{s}$ and, with $D_{T} \sim 0.01 \mathrm{~cm}^{2} / \mathrm{s}$, we expect linear behavior until the melt front penetrates to within roughly $500 \AA$ of the single crystal.

The nature of $\mathrm{Cu}$ and In redistribution profiles after pulsed laser irradiation indicate the mechanism of formation of the FP region. In the case of $\mathrm{Cu}^{+}$implant after $0.2-\mathrm{J} \mathrm{cm}^{-2}$ irradiation, the surface peak is formed in the conventional manner, when the melt front, after penetrating $450 \AA$, retreats toward the surface. Since the distribution coefficient of copper in silicon is considerably lower than unity, the liquid adjacent to the receding melt front becomes progressively more concentrated, finally resulting in surface segregation. The peak or the shoulder near the end of the FP region and the shift of the profile toward the deeper regions provides clear evidence for the movement of a crystallization front downward through the FP region. The redistribution of In at this laser energy exhibits the same features. These observations provide direct evidence for the explosive recrystallization mechanism proposed by Gilmer and Leamy in which the crystallizing front during explosive recrystallization is intermediated by a thin liquid film. ${ }^{16}$

From these observations, we can obtain a rough esti- mate of the velocity of solidification in the LP region and the thickness of the liquid layer during explosive recrystallization. From the fit to As profiles in the LP region in $\mathrm{As}^{+}$implanted samples, using $D_{\mathrm{As}}=3 \times 10^{-4} \mathrm{~cm}^{2} \mathrm{~s}^{-1},{ }^{17}$ we estimate velocity of solidification $3-5 \mathrm{~m} \mathrm{~s}^{-1}$. The average extent of redistribution of arsenic in the FP region is $\leqslant 100 \AA$. Setting this equal to $\sqrt{2 D_{\tau}}$, where $\tau$ is the average amount of time an impurity atom remains in the melt, we obtain $\tau$ $\approx 1.6 \times 10^{-9} \mathrm{~s}$. We also have ${ }^{16} \tau=\delta / k^{\prime} V$, where $\delta$ is the thickness of the propagating liquid film in the FP region at velocity $V$, and $k^{\prime}$ is the nonequilibrium distribution coefficient. Using $V \sim 10-12 \mathrm{~m} \mathrm{~s}^{-1}$, estimated for similar explosive events, ${ }^{6}$ we have $\delta<200 \AA$.

In conclusion, we have observed the formation of two distinct regions, a fine polycrystalline (FP) layer underneath a large polycrystalline (LP) layer, after pulsed laser irradiation of amorphous silicon layers. The thickness of the LP region increases linearly with pulse energy density while that of the (FP + LP) region shows a rapid initial rise with pulse energy density, followed by saturation at the thickness of the original amorphous layer. A heat-flow program that assumes normal melting from and resolidification back to the free surface calculates a maximum depth of melting that corresponds to the thickness of the LP layer only. Accummulation of $\mathrm{Cu}$ and In at the free surface implies motion of a crystal-melt interface upward towards the free surface during growth of the large polycrystals. Similarly, accumulation at the boundary between FP and $\alpha$-Si implies motion of a crystal-melt interface downward towards the bulk during growth of the buried FP layer. The extent of As redistribution in the polycrystalline regions implies a long melt lifetime in the LP region and a very short lifetime in the buried FP region. The nature of impurity redistribution and the microstructures observed indicate that the LP layer formed by regrowth in the conventional manner and that the FP layer formed by explosive crystallization. The thin liquid layer propagating downward during the latter process is estimated to be less than $200 \AA$ wide. When the thickness of L.P is very large, there is evidence for bulk nucleation and growth in a thin near-surface FP layer and in a thin buried FP layer.

\section{ACKNOWLEDGMENT}

We are grateful to $\mathrm{M}$. O. Thompson for making his heat-flow program available to us and for valuable discussions on the electrical conductance and reflectivity during annealing of $\alpha-\mathrm{Si}$.

'C. W. White, J. Narayan, and R. T. Young, Science 204, 461 (1979). ${ }^{2}$ J. Narayan, J. Fletcher, C. W. White, and W. H. Christie, J. Appl. Phys. 52, $7121(1981)$.

${ }^{3} \mathrm{~J}$. Narayan and C. W. White, Appl. Phys. Lett. 44, 35 (1984).

${ }^{4}$ M. O. Thompson, G. J. Galvin, J. W. Mayer, P. S. Peercy, J. M. Poate, D.C. Jacobson, A. G. Cullis, and N. G. Chew, Phys. Rev. Lett. (in press). SJ. Narayan, G. R. Rozgonyi, D. Bensahel, G. Auvert, V. T. Nguyen, and A. K. Rai in Laser-Solid Interactions and Transient Thermal Processing of Materials, edited by J. Narayan, W. L. Brown, and R. A. Lemons (NorthHolland, New York, 1983), p. 177. 
${ }^{6}$ G. Auvert, D. Bensahel, A. Perio, V. T. Nguyen, and G. A. Rozgonyi, Appl. Phys. Lett. 39, 724 (1981).

M. O. Thompson, $\mathrm{Ph}$.D. thesis, Cornell University, 1983.

${ }^{B}$ G. E. Gellison and F. A. Modine, Appl. Phys. Lett. 41, 180 (1982).

${ }^{9}$ G. E. Gellison (unpublished).

${ }^{10}$ T. Papa, F. Scudieri, M. Marinelli, U. Zammit, and G. Cembali, J. Phys. (Paris) Collog. C5, 73 (1983).

'H. C. Webber, A. G. Cullis, and N. G. Chew, Appl. Phys. Lett. 43, 669 (1983).

12J. Narayan, Mater. Lett. 2, 219 (1984).
${ }^{13}$ J. Narayan, O. W. Holland, and B. R. Appleton, J. Vac. Sci. Technol. B1, 871 (1983).

${ }^{14}$ R. F. Wood, D. H. Lowndes, and J. Narayan, Appl. Phys. Lett. 44, 770 (1984).

${ }^{15}$ D. Turnbull, J. Appl. Phys. 21, 1022 (1950).

${ }^{16} \mathrm{G}$. H. Gilmer and H. J. Leamy in Laser and Electron Beam Processing of Materials, edited by C. W. White and P. S. Peercy (Academic, New York, 1980), p. 227.

17S. H. Kodera, Jpn. J. Appl. Phys. 2, 212 (1965) 